\title{
Association of Serum Magnesium Concentration with Alzheimer's Disease
}

\author{
UDDIN MK ${ }^{1}$, HABIB MA ${ }^{2}$, ISLAM MR ${ }^{3}, K^{\prime} H A N M M^{4}$, RAHMAN HZ ${ }^{5}$, RIZVI AN $^{6}$, BHUIYAN MM $^{7}$, \\ BARMAN KK ${ }^{8}$, SHOWKAT $S^{9}$, HANNAN MA ${ }^{10}$, SARKER I ${ }^{11}$
}

\begin{abstract}
:
Background: Alzheimer's disease is a neurodegenerative disease. It is the most common cause of dementia in individuals older than 60 years of age. Age is the most important risk factor for Alzheimer's disease. It is important to identify modifiable risk factors. One such important modifiable risk factor is Magnesium, a trace element. The objective of the study was to see the association of serum Magnesium concentration with Alzheimer's disease patients. Method: It was a case control study carried out in neurology department of BSMMU, Dhaka. Total 68 patients were enrolled as study population after satisfying inclusion and exclusion criteria. Among them, 34 were grouped as case and rest 34 were control. Serum Magnesium concentration was detected. Result: Serum Magnesium concentration was significantly lower in $A D$ patients than that of control group [2.04 $\pm 0.19 \mathrm{mg} / \mathrm{dl}$ vs $2.36 \pm 0.21 \mathrm{mg} / \mathrm{dl}$. Conclusion: The results of our study revealed an expression that the trace element, Magnesium concentration has an association with Alzheimer's disease.
\end{abstract}

Key Words: Alzheimer's dementia, Magnesium concentration, Risk factor etc.

Introduction:

Alzheimer's disease is a progressive and fatal neurodegenerative disorder manifested by cognitive and memory deterioration, progressive impairment of activities of daily living and a variety of neuropsychiatric symptoms and behavioral disturbances.

Alzheimer's disease is the most common form of dementia, accounting for $50-56 \%$ cases at autopsy and in clinical series ${ }^{2}$. More than 35 million people worldwide; 5.5 million in the United States have Alzheimer's disease, a deterioration of memory and other cognitive domains that leads to death within 3-9 years after diagnosis ${ }^{2}$.
Alzheimer disease (AD), specifically the late onset form of $A D$ (LOAD) is common. Although mutation in the genes PS1, PS2, and APP cause less common forms of early-onset, autosomal dominant familial AD (FAD), these cases represent $<1 \%$ of $A D^{3}$.

Exact aetiopathogenesis of Alzheimer's disease is still poorly understood. Well-known hypothesis includes amyloid hypothesis by Hardy and Higgins ${ }^{4}$ in 1992 , by Hardy and Selkoe ${ }^{5}$ in 2002.Many risk factors have been defined in the literature and the roles of environmental factors, nutrition, some vitamins and trace elements have been investigated ${ }^{6,7,8}$.Magnesium is one of the

1. Dr Mohammad Kafil Uddin.Phase-B resident (MD-Neurology), Department of Neurology, BSMMU, Dhaka, Bangladesh.

2. Dr Md. Ahsan Habib.Associate Professor, Department of Neurology, BSMMU, Dhaka, Bangladesh.

3. Dr Md. Rafiqul Islam .Professor \& Chairman, Department of Neurology, BSMMU, Dhaka, Bangladesh.

4. Dr Md . Rezaul Karim Khan.Professor, Department of Neurology, BSMMU, Dhaka, Bangladesh.

5. Dr Hasan Zahidur Rahman. Professor, Department of Neurology, BSMMU, Dhaka, Bangladesh.

6. Dr Abu Nasir Rizvi.Professor, Department of Neurology, BSMMU, Dhaka, Bangladesh.

7. Dr Md. Moniruzzaman Bhuiyan.Professor, Department of Neurology, BSMMU, Dhaka, Bangladesh.

8. Dr Kanuj Kumar Barman.Associate Professor, Department of Neurology, BSMMU, Dhaka, Bangladesh.

9. Dr Syeeda Showkat ,Associate Professor, Department of Radiology \& Imaging, BSMMU, Dhaka, Bangladesh.

10. Dr M.A. Hannan ,Professor, Department of Neurology, BSMMU, Dhaka, Bangladesh.

11. Dr. Imran Sarker, Registrar (Clinical Neurology), NINS\&H, Dhaka, Bangladesh. 
important ions in the central nervous system and dietary deficiency of $\mathrm{Mg}^{2+}$ increases the neurotoxicity 9 . Because of its involvement in a number of bioenergetics and biochemical activities, magnesium appears to play an important role in normal neuronal activity ${ }^{10}$.

Onset of $A D$ is usually insidious. Family members or even the patient himself or herself cannot mention the time of beginning. Clinically it is characterized by loss of memory, inability to learn new things, loss of language function, a deranged perception of space, unable to calculate, depression and other manifestations.

$A D$ is a progressive disorder. Familial occurrence of Alzheimer's disease is also well established. In less than 1 percent of such cases, there is a dominant inheritance pattern with a high degree of penetrance and appearance of disease at a younger age ${ }^{11,12}$. The annual incidence worldwide increases from $1 \%$ between the ages of 60 and 70 years to $6 \%-8 \%$ at the age of 85 years or older ${ }^{13}$.

The most commonly used and widely accepted criteria for Alzheimer's disease is the NINCDSADRDAcriteria ${ }^{14,15}$. This criteria is very useful. For early and presysmptomatic (prodromal) AD diagnosis, a criteria is proposed by Dubois et al. in $2007^{16}$.

There is no definitive investigation to confirm the $A D$. But some helpful investigations are CT/MRI of brain, PET scanning, PET imaging with the use of amyloid-binding compounds, such as carbon 11labeled pitsburgh compound B (PIB) and CSF markers.

Magnesium is the fourth most abundant mineral. It is a cofactor for $>300$ metabolic reactions in the body. Magnesium is the second most abundant divalent cation in serum, exceeded only by calcium ${ }^{17}$. Approximately $1 \%$ of total body magnesium is extracellular. Intracellular concentration of Magnesium is higher than that in serum.

The most common test for the evaluation of magnesium levels and magnesium status in patients is serum magnesium concentration ${ }^{18}$. It is most practicable and inexpensive.
Mg has been shown in vitro to gate cation channels opened by glutamate and particularly those on the $\mathrm{N}$-methyl-D-aspartate (NMDA) receptors. Glutamate binding to NMDA receptors was reduced by $75-80 \%$ in the hippocampus of Alzheimer disease brains. The hypothesis of a link between this loss of glutamatergic transmission and $\mathrm{Mg}$ depletion in the hippocampus in Alzheimer's disease has been proposed. Glick goes further and suggests that Alzheimer's disease involves a defective transport process characterized by both an abnormally low $\mathrm{Mg}$ incorporation and an abnormally high Al incorporation into brain neurons ${ }^{19}$.

\section{Methods:}

It was a case control study. Place of study was Dementia clinic, outpatient and inpatient department of Neurology, BSMMU, Dhaka. Study period was July'16 to March' 18 . Study Population includes all adult patients with clinical diagnosis of $A D$. Patients with $A D$ (as cases) and age and sex matched non-demented patients (as controls) were selected by purposive sampling method.

Inclusion criteria for cases included were patients with diagnosis of Alzheimer's disease (according to NINCDS-ADRDA Criteria), Age- more than 40 years, both male \& female. Exclusion Criteria for cases included were congestive heart failure, acute exacerbation of COPD, acute $\mathrm{Ml}$, uncontrolled hypertension ( $S B P \geq 180 \mathrm{~mm} \mathrm{Hg}$ ), uncontrolled DM, moderate to severe renal or hepatic disease, diseases causing progressive deficit in cognition, Parkinson's disease, subdural hematoma, NPH, Stroke, brain tumor.

Inclusion criteria for control included were nondemented patients (age and sex matched) in inpatient and outpatient department of Neurology, BSMMU. The patients with the diagnosis of tension type headache, migraine, hemifacial spasm, writer's cramp, low back pain, cervical spondylitis, PLID were included as control group.

Exclusion criteria for control included were patients of any type of dementia, patients unwilling to take part in study, drugs causing decreased magnesium level eg. diuretics, ethanol, cisplatin, cyclosporine. 
$\mathrm{H} / \mathrm{O}$ stroke, acute $\mathrm{MI}$, acute or unstable medical conditions, heart failure, malignancy, chronic liver disease, chronic kidney disease were also included in exclusion criteria.

After taking careful history, physical and neurological examination including MMSE was done. The cognitive impairment was assessed by MMSE Score (Mild: 20-24, Moderate: 10-19. Severe: <10). MMSE is a simplified, scored form of the cognitive metal status examination. It includes eleven questions, requires only 5-10 min to administer, and is therefore practical to use serially and routinely ${ }^{20}$.

Relevant investigations including MRI of Brain were done to diagnose AD and to rule out other causes of dementia. Diagnosis of AD was established before doing Serum Mg concentration.

A questionnaire was developed in English. Bengali version of MMSE was reproduced for easy communication. According to specific objectives, the questionnaire was developed using the selected variables. A checklist section was also made for data collection. Before starting data collection, the details of the study were explained to each patient and patient's attendants and informed consent of the respondents was obtained.

At the end of data collection, the mean and standard deviation of Serum Mg levels of both cases and controls were calculated. Quantitative data was analyzed by unpaired $t$ test and qualitative data was analyzed by $\chi^{2}$ (Chi Square) test. The level of significance was set at $\mathrm{P}<0.05$.

\section{Results:}

Table I shows that the mean age $( \pm S D)$ was $63.26 \pm 8.18$ years in case group and $60.23 \pm 8.22$ year in control group. There was no significant difference in age distribution between case and control $(p>0.05)$.In case, $55.9 \%$ were male and $44.1 \%$ were female. Statistically no significant difference was observed between the two groups in term of gender $(p>0.05)$.

Table II shows mean serum magnesium concentration in case group was $2.04 \pm 0.19$, in control group was $2.36 \pm 0.21$.In case group, serum magnesium concentration is significantly less in comparison to control group.

Table III shows the odds ratio between case and control group is 10.63 (95\% Cl:3.26-34.65). The odds ratio 10.63 indicated that serum magnesium concentration below $2.15 \mathrm{mg} / \mathrm{dl}$ can increase the risk of Alzheimer's disease by 10.63 times.

Table IV shows that most of the patients presented with moderate dementia (58.8\%) followed by mild $(23.5 \%)$ and then severe dementia (17.6\%).

Table-I

Distribution of study subjects according to age ( $n=68)$

\begin{tabular}{cccc}
\hline & \multicolumn{2}{c}{ Group } & p value \\
\cline { 2 - 3 } & Case $(\mathrm{n}=34)$ & Control $(\mathrm{n}=34)$ & \\
\hline Age (years) & & & \\
$40-49$ & $1(2.9)$ & $3(8.8)$ & 0.613 \\
$50-59$ & $8(23.5)$ & $11(32.4)$ & 0.416 \\
$60-69$ & $20(58.8)$ & $17(50.0)$ & 0.466 \\
$\geq 70$ & $5(14.7)$ & $3(8.8)$ & 0.709 \\
Mean \pm SD & $63.26 \pm 8.18$ & $60.23 \pm 8.22$ & 0.133 \\
Gender & & & 1.000 \\
Male & $19(55.9)$ & $19(55.9)$ & \\
Female & $15(44.1)$ & $15(44.1)$ & \\
\hline
\end{tabular}


Table-II

Serum magnesium concentration in case and control $(n=68)$

\begin{tabular}{lccc}
\hline Serum magnesium & \multicolumn{2}{c}{ Group } & p value \\
\cline { 2 - 3 } & Case $(n=34)$ & Control $(n=34)$ & \\
\hline Mean \pm SD & $2.04 \pm 0.19$ & $2.36 \pm 0.21$ & $<0.001$ \\
\hline
\end{tabular}

Table-III

Distribution of study subject at $2.15 \mathrm{mg} / \mathrm{dl}$ serum magnesium concentration (cut off value) in case and control $(n=68)$

\begin{tabular}{lcccccc}
\hline & Group & $\mathrm{n}(\%)$ & OR & $95 \% \mathrm{Cl}$ (lower - upper) & p value $^{*}$ \\
\hline Serum & Case & $22(64.7)$ & 10.63 & 3.26 & 34.65 & $<0.001^{\mathrm{s}}$ \\
Magnesium & Control & $5(14.7)$ & & & & \\
$<2.15 \mathrm{mg} / \mathrm{dl}$ & & & & & & \\
\hline
\end{tabular}

Table-IV

Distribution of $A D$ dementia patient according to severity $(n=34)$

\begin{tabular}{lcc}
\hline Dementia & Frequency $(\mathrm{n})$ & Percentage $(\%)$ \\
\hline Mild & 8 & 23.5 \\
Moderate & 20 & 58.8 \\
Severe & 6 & 17.6 \\
\hline
\end{tabular}

Figure 1 shows correlation of serum Magnesium concentration with MMSE score. Here positive correlation coefficient $(r=+0.018)$ was observed which was not statistically significant $(p=0.920)$.

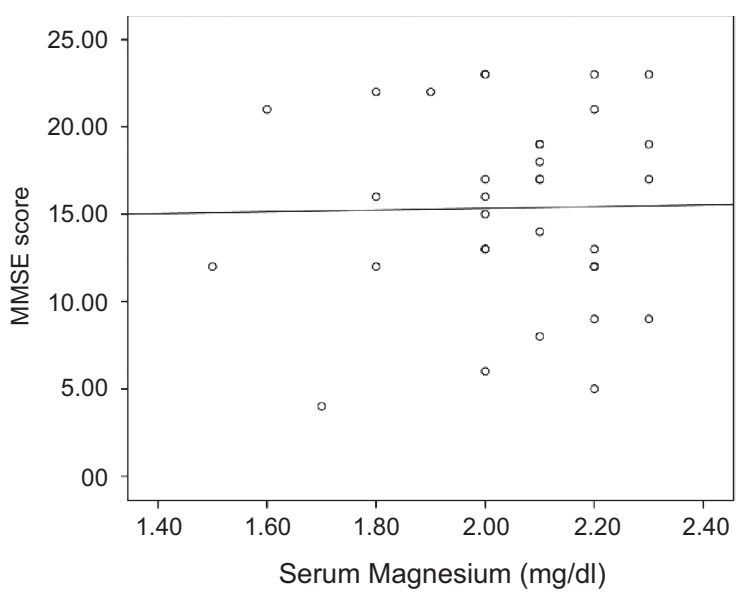

Fig.-1 (Scatter diagram): Correlation of serum Magnesium concentration with MMSE score.
Figure 2 shows correlation of serum Magnesium concentration with duration of dementia. Negative correlation coefficient $(r=-0.196)$ was observed which was not statistically significant $(p=0.250)$.

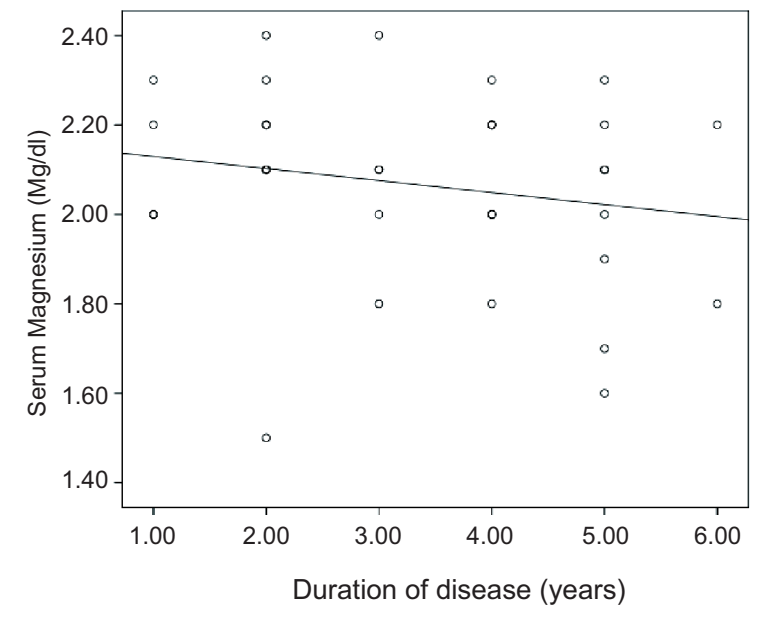

Fig.-2 (Scatter diagram): Correlation of serum Magnesium concentration with duration of dementia.

Discussion:

In this study, analysis of age distribution showed that there was no significant difference in mean age between two groups $(P>0.05)$ It is consistent with studies like Veronese et al. ${ }^{21}$, Lemke et al. ${ }^{22}$, but these age groups seemed to be higher in comparison to our study. It might be due to lower life expectancy of our population. 
Both in case and control group, 55.9\% (19) were male and $44.1 \%$ (15) were female. There was male preponderance both in case and control groups. Statistically no significant difference was observed between the two groups in terms of gender $(p>0.05) . A D$ is more common in female patients in many studies of other countries ${ }^{22,23}$. In the context of our country, female patients have less health seeking behavior. That's why female patients were enrolled less. The mean $( \pm S D)$ value $(\mathrm{mg} / \mathrm{dl})$ of Serum Magnesium concentration in AD patients was found less than that of control group [2.04 \pm 0.19 Vs $2.36 \pm 0.21]$ which is statistically significant $(p<0.001)$. It is consistent with other studies like Vural et al. ${ }^{23}$, Basheer et al. ${ }^{24}$. The cut off value of serum Magnesium was set at $2.15 \mathrm{mg} / \mathrm{dl}$. In this study, below cut off value in case group was $64.7 \%$ and in control group was $14.7 \%$. It is statistically significant $(p<0.001)$. The odds ratio was 10.63 $(95 \% \mathrm{Cl}: 3.26-34.65)$. It indicated that serum magnesium concentration lower than $2.15 \mathrm{mg} / \mathrm{dl}$ can increase the risk of Alzheimer's by 10.63 times.

Outpatient Department of Neurology, BSMMU runs a weekly dementia clinic where dementia patients are evaluated and treated. This study revealed that most patients presented with moderate dementia $(58.8 \%)$. The rest had mild $(23.5 \%)$ and severe dementia (17.6\%).

So we can comment that in agreement with previous studies, in our study serum magnesium concentrations were found to be significantly decreased in $A D$ dementia patients when compared to controls.

\section{Conclusion:}

The present study revealed that serum magnesium concentration was significantly lower in AD patients in comparison to control group. So, this biomarker has association with AD. However, there was no significant relationship between serum magnesium level and severity of disease. Also there was no significant correlation between serum magnesium concentration and duration of AD.

\section{References:}

1. Cummings JL. Alzheimer's Disease. N Engl J Med. 2004;351:56-67.
2. Henry W, QuerfurthHW, LaFerla FM. Mechanisms of disease Alzheimer's disease. New Engl J Med. 2010;362:329-44.

3. Holtzman DM, Herz J, Bu G. Apolipoprotein $E$ and apolipoprotein $E$ receptors: normal biology and roles in Alzheimer disease. Cold Spring Harbor perspectives in medicine. 2012 Jan. 1-17

4. Hardy JA, Higgins GA. Alzheimer's disease: the amyloid cascade hypothesis. Science. 1992 Apr 10;256(5054):184.

5. Hardy J, Selkoe DJ. The amyloid hypothesis of Alzheimer's disease: progress and problems on the road to therapeutics. science. 2002 Jul 19;297(5580):353-6.

6. Basun H, Forssell LG, Wetterberg L, Winblad B. Metals and trace elements in plasma and cerebrospinal fluid in normal aging and Alzheimer's disease. Journal of neural transmission.Parkinson's disease and dementia section. 1991;3(4):231-58.

7. Esposito E, Rotilio D, Di Matteo V, Di Giulio $C$, Cacchio M, Algeri S. A review of specific dietary antioxidants and the effects on biochemical mechanisms related to neurodegenerative processes. Neurobiology of aging. 2002 Sep 1;23(5):719-35.

8. Jama JW, Launer LJ, Witteman JC, Den Breeijen JH, Breteler MM, Grobbee DE, et al. Dietary antioxidants and cognitive function in a population-based sample of older persons: the Rotterdam study. American journal of epidemiology. 1996 Aug 1;144(3):275-80.

9. Mitani K. Relationship between neurological diseases due to aluminium load, especially amyotrophic lateral sclerosis, and magnesium status. Magnesium research. 1992 Sep; 5(3):203-13.

10. Altura BT, Altura BM. A method for distinguishing ionized, complexed and protein-bound $\mathrm{Mg}$ in normal and diseased subjects.Scandinavian Journal of Clinical and Laboratory Investigation. 1994 Jan 1;54 (sup217):83-7. 
11. Nee LE, Eldridge R, Sunderland T, Thomas CB, Katz D, Thompson KE, Weingartner $H$, Weiss $H$, Julian C, Cohen R. Dementia of the Alzheimer type Clinical and family study of 22 twin pairs. Neurology. 1987 Mar,37(3):359-63

12. Goudsmit JA, White BJ, WeitkampLR, Keats BJ, Morrow CH, Gajdusek DC. Familial Alzheimer's disease in two kindreds of the same geographic and ethnic origin: A clinical and genetic study. Journal of the neurological sciences. 1981 Jan 1;49(1):79-89.

13. Mayeux R. Epidemiology of neurodegeneration. Annual review of neuroscience. 2003 Mar;26(1):81-104.

14. McKhann G, Drachman D, Folstein M, Katzman R, Price D, Stadlan EM. Clinical diagnosis of Alzheimer's disease Report of the NINCDS ADRDA Work Group* under the auspices of Department of Health and Human Services Task Force on Alzheimer's Disease. Neurology. 1984 Jul 1;34(7):939.

15. Tierney MC, Fisher RH, Lewis AJ, Zorzitto ML, Snow WG, Reid DW, et al. The NINCDS ADRDA Work Group criteria for the clinical diagnosis of probable Alzheimer's disease Aclinicopathologic study of 57 cases. Neurology. 1988 Mar 1;38(3):359.

16. Dubois B, Feldman HH, Jacova C, DeKosky ST, Barberger-Gateau P, Cummings J, Delacourte A, Galasko D, Gauthier S, Jicha $G$, Meguro K. Research criteria for the diagnosis of Alzheimer's disease: revising the NINCDS-ADRDA criteria. The Lancet Neurology. 2007 Aug 1;6(8):734-46.

17. Kroll MH, Elin RJ. Relationships between magnesium and protein concentrations in
serum.Clinical chemistry. 1985 Feb 1;31(2):244-6.

18. Touyz RM. Magnesium in clinical medicine. Front Biosci. 2004 May 1;9(1-3):1278-93.

19. Durlach J. Magnesium depletion and pathogenesis of Alzheimer's disease. Magnesium research. 1990 Sep;3(3):217-8.

20. Folstein MF, Folstein SE, McHugh PR. "Minimental state": a practical method for grading the cognitive state of patients for the clinician. Journal of psychiatric research. $1975 \mathrm{Nov}$ 1;12(3):189-98.

21. Veronese N, Zurlo A, Solmi M, Luchini C, Trevisan C, Bano G, et al. Magnesium status in Alzheimer's disease: a systematic review. American Journal of Alzheimer's Disease\& Other Dementias ${ }^{\circledR} .2016$ May;31(3):208-13.

22. Lemke MR. Plasma magnesium decrease and altered calcium/magnesium ratio in severe dementia of the Alzheimer type. Biological psychiatry. 1995 Mar 1;37(5): 341-3.

23. Vural H, Demirin H, Kara Y, Eren I, Delibas N. Alterations of plasma magnesium, copper, zinc, iron and selenium concentrations and some related erythrocyte antioxidant enzyme activities in patients with Alzheimer's disease. Journal of Trace Elements in Medicine and Biology. 2010 Jul 1;24(3):169-73.

24. Basheer MP, Kumar KP, Sreekumaran E, Ramakrishna T. A study of serum magnesium, calcium and phosphorus level, and cognition in the elderly population of South India.Alexandria Journal of Medicine. 2016;52(4):303-8. 